\title{
Nutrient transport and transformation in macrotidal estuaries of the French Atlantic coast: a modelling approach using C-GEM
}

Xi Wei ${ }^{1 *}$, Josette Garnier ${ }^{*}$, Vincent Thieu ${ }^{1}$, Paul Passy ${ }^{2}$, Romain Le Gendre ${ }^{3}$, Gilles Billen ${ }^{1}$, Maia Akopian $^{4}$, and Goulven Gildas Laruelle ${ }^{5}$

1 UMR Metis 7619, Sorbonne Université, CNRS EPHE, 4 Place Jussieu, Paris, 75005, France

2 UMR 8586 PRODIG, Université de Paris, 8 rue Albert Einstein, 75013 Paris, France

3 Ecosystèmes et Aquaculture Durable, Unité de Recherche Lagons, IFREMER, Noumea, 98897, New-Caledonia

4 Department of Research and Scientific Support, French Biodiversity Agency (OFB), 5 square Félix Nadar, 94300 Vincennes, France

5 Department of Geosciences, Environment and Society, Université Libre de Bruxelles, Brussels, 1050, Belgium

Correspondence to: Xi Wei (xi.wei@upmc.fr; xi.wei_fr@hotmail.com); Josette Garnier (josette.garnier@upmc.fr).

Due to the limited space in the main context, the results of small estuaries (the Somme and Vilaine) are presented in the supplement. 


• Observation $\quad$ Simulation Max $\quad--$ Simulation Min

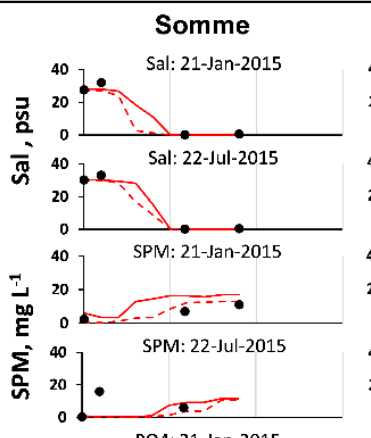

Vilaine
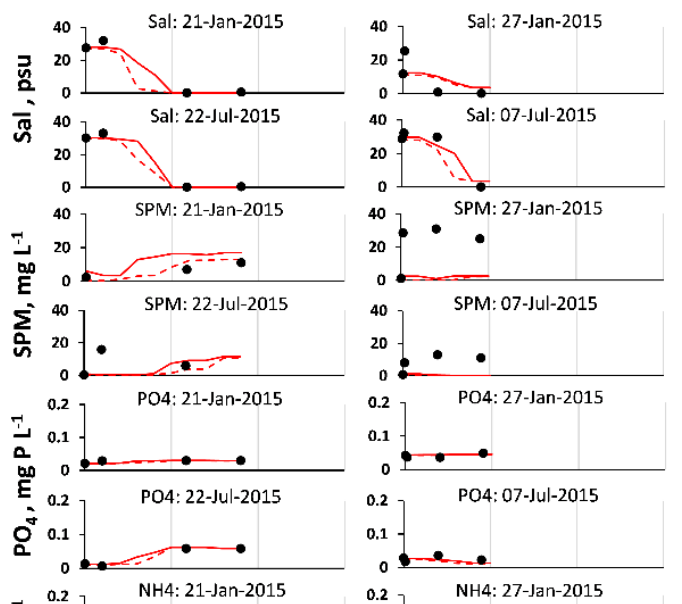

$0.2 \quad P O 4: 27-J a n-2015$ 0.1 -

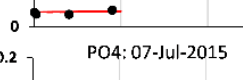
0.1
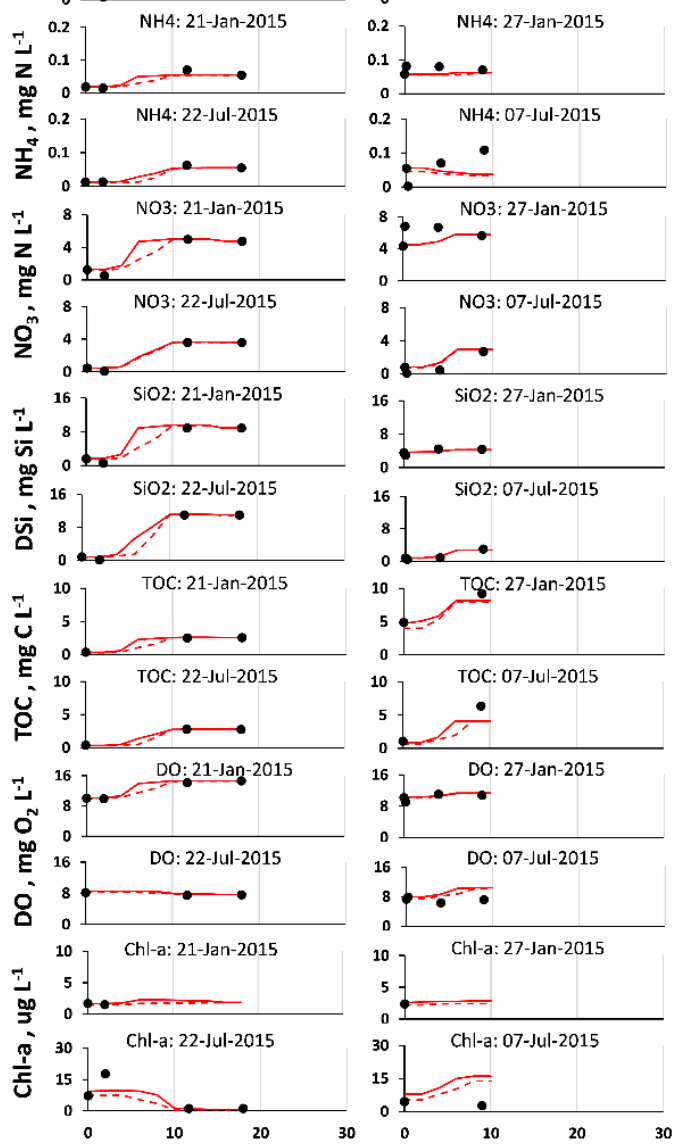

Distance from the sea mouth, $\mathrm{km}$

Figure S- 1 Salinity (Sal), suspended particulate matter (SPM) and nutrients (PO4, NH4, NO3, DSi, TOC), dissolved oxygen (DO), chlorophyll a (Chl-a) concentrations variations along the estuaries (the Somme and Vilaine) for two selected dates (one in winter and the other one in summer). Note the different scales for the Chl-a for the estuaries. 


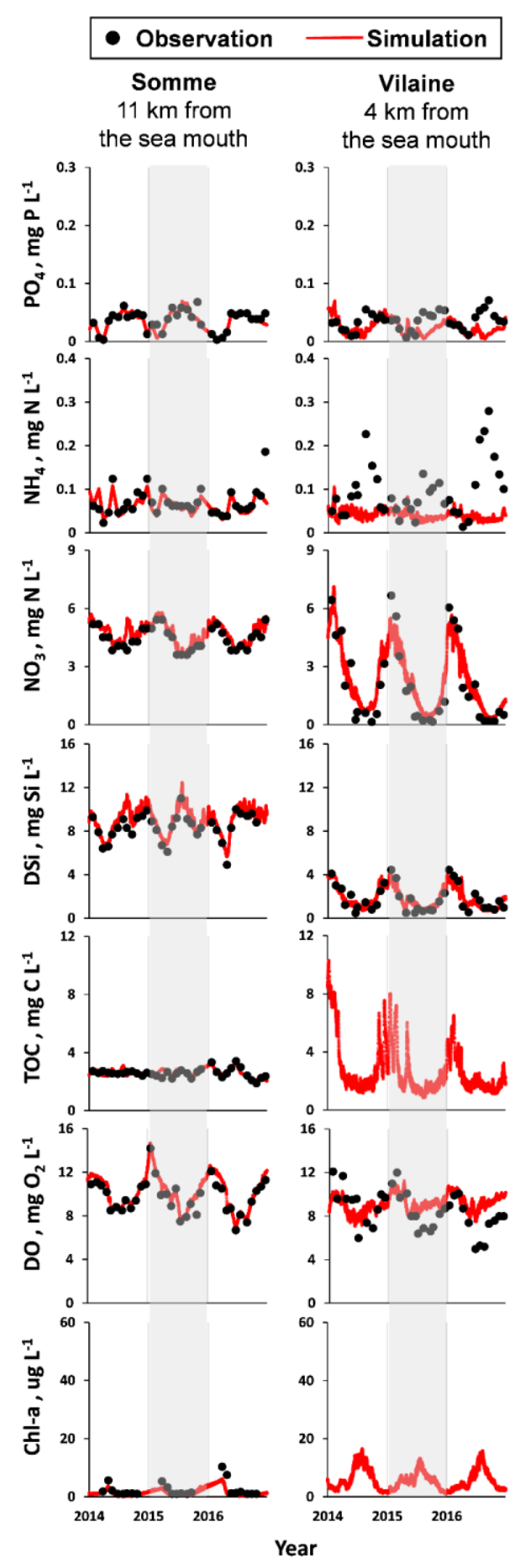

Figure S- 2 Temporal variations for phosphate (PO4), ammonium (NH4), nitrate (NO3), dissolved silica (DSi), total organic carbon (TOC), dissolved oxygen (DO), and chlorophyll a (Chl-a) concentrations from 2014 to 2016 for the Somme and Vilaine estuaries at the sampling stations located about $1 / 2$ the length of the estuary to the sea mouth. Gray columns covered the year of calibration (2015). 